\title{
Informatics About Fear to Report Rapes Using Bumped-Up Poisson Model
}

\author{
Ramalingam Shanmugam \\ School of Health Administration, \\ Texas State University, San Marcos, TX 78666, USA
}

Received 2013-10-17, Revised 2013-10-25; Accepted 2013-11-04

\begin{abstract}
The rape victims are frightened to report with a fear of retaliation or humiliation. Consequently, the number of reported rapes is under-estimated. How should the number of unreported rapes be identified is discussed in this article. For this purpose, the Poisson distribution is modified and it is named Bumped-up Poisson distribution in this article. Related probability-informatics are derived to estimate the unreported rapes and proportion fearing to report. A hypothesis testing procedure is developed to assess the significance of an estimated proportion fearing. Our approach is tried with the reported rapes during the years 2007 and 2008 in a random sample of nations in all the continents. Proximities among the nations are identified in rape incidences.
\end{abstract}

Keywords: Prevalence, Conditional Probability, Likelihood, Odds Ratio

\section{INTRODUCTION}

A loss of mental health exists among the rape victims. Abrahms et al. (2003); McKibbin et al. (2008); Marnie et al. (2005); Thornhill and Palmer (2000); Pauwels (2002) and Buddie and Miller (2001) for details. It is a concern to their families and healthcare professionals. Macdonalds (2003) compiled information about the rapes and related health issues. The local and federal governments exercise efforts to prevent rape and rectify its damages. Still, rapes occur. The rape victims need assistance to recover from traumas including social withdrawals, discomforts, irritability, anger, hostility. Rape crisis centers are established to help the victims. The agencies which finance assistance centers need to estimate the rape prevalence to prepare their budgets. Not all rapes get reported as the victims are threatened or humiliated to report it no matter whether a Randomized Response Technique (RRT) is resorted. For evidence, CPR (2007) notes that $95 \%$ of the rapes are never reported. To improve the reporting, the data collection processes could be refined using advanced survey techniques such as the Randomized Response Technique (RRT). The RRT increases the truthful responses. In a sensitive matters like the rape, the respondents to a survey are suspicious and hesitate to report their rape due to fear. Sivaprakash and Sakthivel (2010) on issues related the connection between safety and fear in all walks of life. Hence, the number of rapes is under-estimated. An approach is necessary to make an upward adjustment. This is possible by bumping-up the usual binomial distribution. But, the number of rapes, $\mathrm{Y}$ is smaller compared to the nation's population size n. An approximation helps and it is named Bumped-up Poisson Distribution (BPD). Basic properties of the BPD are derived and used to estimate the number of unreported rapes for a random sample of nations in the continents: Africa, Americas, Asia, Europe and Pacific based on the reported rape data (in http://www.unodc.org/) for the two years 2007 and 2008. The estimated proportion of victims fearing to report rape and ratio of unreported over reported rapes are compared among the nations in each continent. Furthermore, the proximities among the nations within a continent are identified using the Principal Component Analysis (PCA) of the estimated results. The differences among the nations in the continents are discussed. Some comments are made in the end. 


\section{DERIVATION OF BUMPED-UP POISSON DISTRIBUTION AND PROBABILITY-INFORMATICS}

Note that the expected number, $\mathrm{E}(\mathrm{Y})$ of rapes in a nation is its population size, $\mathrm{n}$ times the probability, $0<$ $\pi<1$ for a rape to occur during a year. In an unsafe nation, this rape probability is higher than zero. The cases, $\pi=0$ and $\pi=1$, are excluded as extremes. Its estimate $\pi$ is smaller than its true number because many rapes are unreported due to the victim's fear. Even if RRT is resorted, the rape victim feels uncomfortable to report it. Therefore, an approach is necessary to rectify the under-estimation and it is pursued below.

Let $0 \leq \phi<1$ be an unknown probability for a rape victim to fear to report. The case $\phi=0$ is rare but refers the absence of fear. It is due to cultural or legal protections. The case $\phi=1$ is excluded as a helpless scenario in which no data are available. This article blends $\phi$ and $\pi$ with Y to come up with an underlying model for the reported and unreported rapes. To be rigorous, let $\mathcal{R}$ and $\mathrm{H}$ denote "reporting a rape" and "existence of fear of retaliation or humiliation". Suppose their probabilities are $\operatorname{Pr}(\mathcal{R})$ and $\operatorname{Pr}(\mathrm{H})=\phi$. Under fear, there is no chance for the victim to report a rape (that is, $\operatorname{Pr}(\mathcal{R} \mid \mathrm{H})=0$ ). Under no fear, there is a finite chance for the victim to report a rape (that is, $\operatorname{Pr}(\mathcal{R} \mid \overline{\mathrm{H}})=\mathrm{p}$ ) where $\overline{\mathrm{H}}$ denotes the absence of fear. Under no fear, the number, $\mathrm{Y}$ of rapes in a nation follows a binomial distribution Equation (1):

$$
\begin{aligned}
& \operatorname{Pr}(\mathrm{Y}=\mathrm{y})=\left(\begin{array}{l}
\mathrm{n} \\
\mathrm{y}
\end{array}\right) \mathrm{p}^{\mathrm{y}}(1-\mathrm{p})^{\mathrm{n}-\mathrm{y}}, \\
& \mathrm{y}=0,1,2, \ldots, \mathrm{n}, 0<\mathrm{p}<1
\end{aligned}
$$

When fear exists, the binomial distribution (1) for Y is insufficient to be an underlying model. Using (1) to analyze the rape data imposes a bias that no rape victim possesses any fear. Is it true? Obviously, such is not the reality in any nation. If the absence of fear is true, then the proportion of rapes in a nation is not an under-estimate and it is a contradiction to what is in the CPR (2007). A modification to (1) is warranted. We proceed as follows. The unconditional and conditional probabilities to report a rape are connected (Fig. 1) via:

$$
\operatorname{Pr}(\Re)=\operatorname{Pr}(\mathrm{H}) \operatorname{Pr}(\Re \mid H)+\operatorname{Pr}(\overline{\mathrm{H}}) \operatorname{Pr}(\Re \mid \overline{\mathrm{H}})
$$

That is Equation (2):

$$
\pi=\phi(0)+(1-\phi) p
$$

meaning the reported and unreported proportions of rape are respectively $\hat{\pi}$ and:

$$
\hat{\operatorname{Pr}}(\text { rape_is_unreported })=\left(\frac{\hat{\phi}}{1-\hat{\phi}}\right) \hat{\pi}
$$

where, $\left(\frac{\hat{\phi}}{1-\hat{\phi}}\right)$ is the estimated odds to fear. The binomial model (1) is now refined using triangular relation $\mathrm{p}=\frac{\pi}{1-\phi}$ due to (2). An appropriate underlying model for the number, Y of rapes is therefore Equation (3):

$$
\begin{aligned}
& \operatorname{Pr}(\mathrm{Y}=\mathrm{y} \mid \pi, \phi) \\
& =\left(\begin{array}{l}
\mathrm{n} \\
\mathrm{y}
\end{array}\right)\left(\frac{\pi}{1-\phi}\right)^{\mathrm{y}}\left(1-\frac{\pi}{1-\phi}\right)^{\mathrm{n}-\mathrm{y}}, \\
& \mathrm{y}=0,1,2, \ldots, \mathrm{n}, \\
& 0<\pi<1-\phi, 0 \leq \phi<1
\end{aligned}
$$

The model (3) is named BBD. Because the population size is larger (that is, $n \rightarrow \infty$ ) and the probability to report a rape is smaller (that is, $\pi \rightarrow 0$ ), an approximation to BBD (3) helps. That is Equation (4):

$$
\begin{aligned}
& \operatorname{Pr}(Y=y \mid \lambda, \phi) \\
& =\lim _{\substack{n \rightarrow \infty \\
\pi \rightarrow 0 \\
\lambda=n \pi}}\left(\begin{array}{l}
\mathrm{n} \\
\mathrm{y}
\end{array}\right)\left(\frac{\pi}{1-\phi}\right)^{\mathrm{y}}\left(1-\frac{\pi}{1-\phi}\right)^{\mathrm{n}-\mathrm{y}} \\
& =\mathrm{e}^{-\left(\frac{\lambda}{1-\phi}\right)}\left(\frac{\lambda}{1-\phi}\right)^{\mathrm{y}} / \mathrm{y} !, \\
& \mathrm{y}=0,1,2, . ., ; 0 \leq \phi<1 ; \lambda>0
\end{aligned}
$$

Which is called Bumped-up Poisson Distribution (BPD). The expected number, $\mathrm{E}(\mathrm{Y} \mid \pi, \phi)$ of the BPD (4) is Equation (5):

$$
\mathrm{E}(\mathrm{Y} \mid \lambda, \phi \neq 0)=\left(\frac{\lambda}{1-\phi}\right)
$$

Notice the expected number (5) reduces to Equation (6a):

$$
\mathrm{E}(\mathrm{Y} \mid \lambda, \phi=0)=\lambda
$$

When there is a negligible (that is, $\phi \rightarrow 0$ ) or no fear. The difference between (5) and (6a) is the expected number of unreported rapes Equation (6b):

$$
\begin{aligned}
& \mathrm{E}(\text { Unreported_rape } \mid \lambda, \phi) \\
& =\lambda\left(\operatorname{Odds}_{\phi}\right)
\end{aligned}
$$




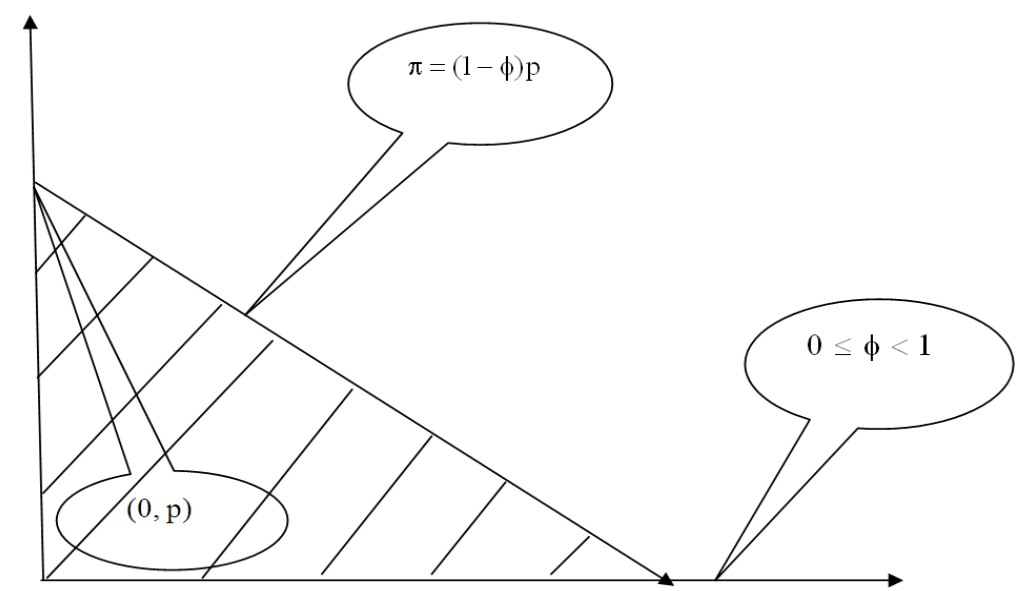

Fig. 1. Triangular relation among $\pi, \phi, p$

The unreported rapes increases whenever the odds of fear or the rape incidence rate increases. The variance $\operatorname{var}(\mathrm{Y} \mid \lambda, \phi)$ of the BPD (4) is Equation (7):

$$
\operatorname{var}(\mathrm{Y} \mid \lambda, \phi)=\mathrm{E}(\mathrm{Y} \mid \lambda, \phi)
$$

The variance measures volatility. Note that volatility increases when the expected number of rapes increases. To check whether the data supports adherence of law and order to uphold a tolerance number $(\tau-1)$ of rapes, the Survival Function (SF) $\operatorname{Pr}(\mathrm{Y} \geq \tau \mid \lambda$, $\phi)$ of $\operatorname{BPD}$ (4) is useful. In specific, when $\tau=1$, it is a zero tolerance. What is the probability that zero tolerance policy is broken? This article explores it for a random sample of nations in each continent. The SF for BPD (4) is Equation (8a):

$$
\begin{aligned}
& \operatorname{Pr}(\mathrm{Y} \geq \tau \mid \lambda, \phi) \\
& =\operatorname{Pr}\left[\chi_{(2 \tau) \mathrm{DF}}^{2} \leq \frac{2 \lambda}{(1-\phi)}\right]
\end{aligned}
$$

where, $\operatorname{Pr}\left[\chi_{\mathrm{mDF}}^{2} \leq \mathrm{z}\right]$ is the Chi-squared distribution function with $m$ Degrees of Freedom (DF). The odds of breaking the zero tolerance rape policy is $\frac{\operatorname{Pr}(\mathrm{Y}>0 \mid \lambda, \phi \neq 0)}{\operatorname{Pr}(\mathrm{Y}=0 \mid \lambda, \phi \neq 0)} \approx\left(\frac{\lambda}{1-\phi}\right)$ under the existence of fear. In an ideal scenario with no fear (that is, $\phi=0$ ), the SF (8a) reduces to Equation $(8 \mathrm{~b})$ :

$$
\begin{aligned}
& \operatorname{Pr}(\mathrm{Y} \geq \tau \mid \lambda, \phi=0) \\
& =\operatorname{Pr}\left[\chi_{(2 \tau) \mathrm{DF}}^{2} \leq 2 \lambda\right]
\end{aligned}
$$

The odds of breaking the zero tolerance rape policy in the absence of fear is $\frac{\operatorname{Pr}(\mathrm{Y}>0 \mid \lambda, \phi=0)}{\operatorname{Pr}(\mathrm{Y}=0 \mid \lambda, \phi=0)} \approx \lambda$ which is lesser than the similar odds in the presence of fear. Their difference $\lambda\left(\mathrm{Odds}_{\phi}\right)$ portrays the extra odds to break the zero tolerance and it increases as the odds of fear or the rape incidence rate increases. In an ideal nation with no fear (that is, $\phi=0$ ), this extra odds becomes negligible. Otherwise, there is a dire need to strengthen the rape related laws or stricter enforcement of the existing laws.

We now proceed to estimate the parameters. Consider a random sample $y_{1}, y_{2}, . ., y_{r}$ of size $r \geq 2$ from BPD (4). Let $\bar{y}=\sum_{i=1}^{r} y_{i} / r$ and $s_{y}^{2}=\sum_{i=1}^{r}\left(y_{i}-\bar{y}\right)^{2} /(r-1)$ denote the sample mean and variance respectively. The Maximum Likelihood Estimators (MLEs) are preferable over other estimators because of its invariance property (Stuart and Ord, 2009). The log-likelihood function is Equation (9):

$$
\begin{aligned}
& \ln \mathrm{L}(\phi, \lambda)=\mathrm{ry}\left[\ln \lambda-\frac{\lambda}{1-\phi}-\ln (1-\phi)\right] \\
& -\sum_{\mathrm{i}=1}^{\mathrm{r}} \ln \mathrm{y} !
\end{aligned}
$$

Solving simultaneously the score functions $\partial_{\lambda} \operatorname{InL}=0$ and $\partial_{\lambda} \ln L=0$ and $\partial_{\phi} \operatorname{lnL}=0$, the MLEs in (13) and (14) are obtained. That is Equation (10):

$$
\hat{\phi}_{\mathrm{mle}}=\left|\frac{\mathrm{s}_{\mathrm{y}}^{2}-\overline{\mathrm{y}}}{\mathrm{s}_{\mathrm{y}}^{2}+\bar{y}}\right|
$$

And Equation (11): 


$$
\begin{aligned}
& \hat{\lambda}_{\text {mle }, \hat{\phi}}=\bar{y}\left|\left(1-\hat{\phi}_{\text {mle }}\right)\right| \\
& =2 \bar{y}\left(\frac{\bar{y}}{\bar{y}+s_{y}^{2}}\right)
\end{aligned}
$$

In a data, when the sample variance converges to mean (that is, $s_{y}^{2} \rightarrow \bar{y}$ ), a characteristic property of regular Poisson distribution, the MLE of the fear factor becomes negligible (that is, $\hat{\phi}_{\text {mle }} \rightarrow 0$ ) and the rape incidence rate converges to the rate under no fear (that is, $\hat{\lambda}_{\text {mle }, \hat{\phi}} \rightarrow \bar{y}$ ). Does it happen? We will examine it now using Wald (1943) Likelihood Ratio Test (LRT). Under an assumption $\phi=\phi^{*} \in[0,1)$, the Wald likelihood ratio in general is Equation (12):

$$
\begin{aligned}
& -\ln \Re_{*}=-\ln \mathrm{L}\left(\phi_{*}, \hat{\lambda}_{\text {mle, } \phi=\phi_{*}}\right) \\
& +\ln \mathrm{L}\left(\hat{\phi}_{\mathrm{mle}}, \hat{\lambda}_{\text {mle }, \hat{\phi}_{\text {mle }}}\right) \\
& =\operatorname{ry}\left(\hat{\phi}_{\text {mle }}+\phi_{*}\right)\left|\left(\hat{\phi}_{\text {mle }}-\phi_{*}\right)\right|
\end{aligned}
$$

which follows a non-central chi-squared distribution with non-centrality parameter Equation (13):

$$
\delta_{*}=\left|\frac{\left(\hat{\phi}_{\mathrm{MLE}}-\phi^{*}\right)}{\operatorname{var}\left(\hat{\phi}_{\mathrm{MLE}}\right)}\right|
$$

where, $\operatorname{var}\left(\phi_{\mathrm{MLE}}\right)$ is a diagonal element of the covariance matrix:

$$
\Sigma=\left[\begin{array}{cc}
\operatorname{var}\left(\hat{\phi}_{\mathrm{MLE}}\right) & \operatorname{cov}\left(\hat{\phi}_{\mathrm{MLE}}, \hat{\lambda}_{\mathrm{MLE}, \hat{\phi}_{\mathrm{MLE}}}\right) \\
\operatorname{cov}\left(\hat{\phi}_{\mathrm{MLE}}, \hat{\lambda}_{\mathrm{MLE}, \hat{\phi}_{\mathrm{MLE}}}\right) & \operatorname{var}\left(\hat{\lambda}_{\mathrm{MLE}, \hat{\phi}_{\mathrm{MLE}}}\right)
\end{array}\right]
$$

The covariance matrix is the inverse of the information matrix I $=\mathrm{E}\left[\begin{array}{ll}-\partial_{\phi \phi}^{2} \ln \mathrm{L} & -\partial_{\phi \lambda}^{2} \ln \mathrm{L} \\ -\partial_{\lambda \phi}^{2} \ln \mathrm{L} & -\partial_{\lambda \lambda}^{2} \ln \mathrm{L}\end{array}\right]$ evaluated at their MLEs $\left(\hat{\phi}_{\mathrm{MLE}}, \hat{\lambda}_{\mathrm{MLE}, \hat{\phi}_{\mathrm{MLE}}}\right)$. After simplifications, we note that $I=\left[\begin{array}{cc}\frac{r \lambda}{(1-\phi)^{3}} & -\frac{r}{(1-\phi)^{2}} \\ -\frac{r}{(1-\phi)^{2}} & \frac{r}{\lambda(1-\phi)}\end{array}\right]$, whose determinant is zero. The regular inverse is not possible because of the singularity. But, its generalized inverse $\mathrm{I}^{-}$is possible in the sense $\mathrm{II}^{-} \mathrm{I}=\mathrm{I}$ (Schott, 2005). Such a generalized inverse is $\Sigma=I^{-}=\left[\begin{array}{cc}\frac{r}{\lambda(1-\phi)} & 0 \\ 0 & 0\end{array}\right]$. The estimate of the non-centrality parameter is Equation (14):

$$
\begin{aligned}
& \hat{\delta}_{*}=\frac{\hat{\lambda}_{\text {mle }}\left(1-\hat{\phi}_{\text {mle }}\right)\left|\left(\hat{\phi}_{\text {mle }}-\phi_{*}\right)\right|}{\mathrm{r}} \\
& =\frac{\bar{y}\left(1-\hat{\phi}_{\text {mle }}\right)^{2}\left|\left(\hat{\phi}_{\text {mle }}-\phi_{*}\right)\right|}{\mathrm{r}}
\end{aligned}
$$

It is known (Stuart and Ord, 2009) that a non-central chi-squared distribution with a non-centrality parameter $\delta$ is approximately $\left(1+\frac{\delta}{1+\delta}\right)$ times the central chi-squared distribution with $\left(\frac{[1+\delta]^{2}}{1+2 \delta}\right)$ DF. The null hypothesis $\mathrm{H}_{0}$ : $\phi=0$ is then rejected in favor of the research hypothesis $\mathrm{H}_{1}: \phi>1$, when $-\ln \Lambda_{0}=\mathrm{r} \overline{\mathrm{y}}\left(\hat{\phi}_{\text {mle }}\right)^{2}$ exceeds its critical

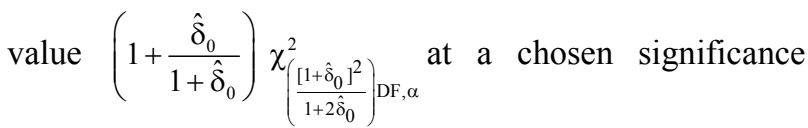
level, $\alpha$. In other words, the p-value to reject the null in favor of the research hypothesis is Equation (15):

$$
\begin{aligned}
& \mathrm{p} \text { - value } \\
& \approx \operatorname{Pr}\left[\chi_{\left(\frac{\left(1+\hat{\hat{\alpha}}_{0}\right]^{2}}{1+2 \hat{\delta}_{0}}\right) \mathrm{DF}}>\frac{\mathrm{r} \bar{y}\left(\hat{\phi}_{\mathrm{mle}}\right)^{2}}{\left(1+\frac{\hat{\delta}_{0}}{1+\hat{\delta}_{0}}\right)}\right]
\end{aligned}
$$

The power is the probability of accepting a true specific research hypothesis in an event $\phi^{*}=\phi_{1} \neq 0$. Recall $-\ln \Lambda_{1}=\operatorname{ry}\left(\hat{\phi}_{\text {mle }}+\phi_{1}\right)\left|\left(\hat{\phi}_{\text {mle }}-\phi_{1}\right)\right|$ that. That is, for a specified significance level, $\alpha$ Equation (16):

$$
\operatorname{Pr}\left[\chi_{\left(\frac{\left.1+\hat{\delta}_{1}\right]^{2}}{1+2 \hat{\delta}_{1}}\right) \text { DF }}^{\text {power } \approx}<\frac{\left.\left(1+\frac{\hat{\delta}_{0}}{1+\hat{\delta}_{0}}\right)\left(1-\left[\frac{\phi_{1}}{\hat{\phi}_{\mathrm{mle}}}\right]^{2}\right) \chi_{\left(\frac{\left.1+\hat{\delta}_{0}\right]^{2}}{1+2 \hat{\delta}_{0}}\right) \mathrm{DF}, \alpha}^{2}\right]}{\left(1+\frac{\hat{\delta}_{1}}{1+\hat{\delta}_{1}}\right)}\right]
$$

\section{ILLUSTRATION OF RAPES IN CONTINENTS}

In this section, the results are illustrated using the reported rapes (in http://www.unodc.org) for sampled nations of the continents: Africa, Americas, Asia, Europe and Pacific during the two years: 2007 and 2008. See the 
web http://www.unodc.org/CTS12_Sexual_violence.xls for the data whose results are in Table 1-5. The sample size is $\mathrm{r}$ $=2$. Note that $\mathrm{Y}_{\mathrm{i}}, \mathrm{i}=1,2, . . \mathrm{r}, 0 \leq \phi \leq 1, \lambda>0$ and $\mathrm{n}$ denote respectively the reported rapes, the proportion of rape victims with fear and the rate of reported rapes and the population size. Their MLEs are $\hat{\phi}_{\mathrm{mle}}=\frac{\mathrm{s}_{\mathrm{y}}^{2}-\overline{\mathrm{y}}}{\mathrm{s}_{\mathrm{y}}^{2}+\overline{\mathrm{y}}}$ and $\hat{\lambda}_{\text {mle }, \hat{\phi}}=\frac{\overline{\mathrm{y}}\left|\left(1-\hat{\phi}_{\text {mle }}\right)\right|}{\mathrm{r}}$ respectively. The null hypothesis $\mathrm{H}_{0}: \phi$ $=0$ refers a negligible fear. Suppose that a half of the rape victims live in fear is the specific research hypothesis (that is, $\mathrm{H}_{1}:=\phi=\phi^{*}=0.5$ ). The MLE of fearing proportion, estimated ratio of unreported rapes over reported rapes, power and the number fearing for ten non-fearing are displayed in the Table 1-5 below respectively for the nations in the continents: Africa, Americas, Asia, Europe and Pacific. The fear to report a rape is insignificant in Argentina, Canada, Azerbaijan, Kuwait, Maldives, Tajikistan andorra, Bosnia and Herzegovina, Bulgaria, France, Luxembourg, Moldova, Serbia and Switzerland. The power of accepting the true research hypothesis $\mathrm{H}_{1}$ : = $\phi^{*}=0.5$ is high in many nations except Lesotho, Argentina, Mexico, Peru, USA, India, Philippines andorra, Belgium, Germany, Netherlands, Rumania, Spain, UK (England and Wales), The unreported rapes are higher than the reported rapes in Algeria, Colombia, Grenada, Hong Kong, Israel, Kyrgyzstan, Mongolia, Albania andorra, Austria, Hungary, Ireland, Latvia, Norway, Portugal, Ukraine, Australia, New Zealand and Solomon Islands.

Table 1. Rapes in Africa $(* *=p$-value $<0.001, *$ p-value $<0.01)$

\begin{tabular}{|c|c|c|c|c|c|}
\hline African & $\hat{\phi}$ & $\hat{\lambda}_{1}\left(\frac{\hat{\phi}}{1-\hat{\phi}}\right)$ & $\hat{\lambda}_{0}$ (reported rapes & Power $=\operatorname{Pr}($ accept & $\left(\frac{\hat{\phi}}{1-\hat{\phi}}\right)$ (\#fear_ \\
\hline Nations $(r=11)$ & (Prop fear) & $\begin{array}{l}\text { (unreported rapes } \\
\text { under fear) }\end{array}$ & without fear) & true $\phi_{*}=0.5$ ) & for 10 Non-fear) \\
\hline Algeria & $0.48^{* *}$ & 1136 & 824 & 0.440 & 9 \\
\hline Kenya & $0.85 * *$ & 685 & 806 & 0.740 & 56 \\
\hline Lesotho & $0.28 * *$ & 518 & 1838 & 0.001 & 3 \\
\hline Mauritius & $0.39 *$ & 65 & 73 & 0.910 & 6 \\
\hline Morocco & $0.51 * *$ & 598 & 1173 & 0.330 & 10 \\
\hline Mozambique & $0.42 *$ & 45 & 44 & 0.850 & 7 \\
\hline Senegal & $0.98 * *$ & 286 & 292 & 0.910 & 526 \\
\hline Sierra Leone & $0.87 * *$ & 93 & 107 & 0.920 & 68 \\
\hline South Africa & $0.99 * *$ & 66765 & 67166 & 0.930 & 1663 \\
\hline Uganda & $0.99 * *$ & 1062 & 1067 & 0.910 & 2051 \\
\hline Zimbabwe & $0.99 * *$ & 3949 & 3974 & 0.920 & 1557 \\
\hline
\end{tabular}

Table 2. Rapes in Americas $(* *=p$-value $<0.001, *$ p-value $<0.01)$

\begin{tabular}{|c|c|c|c|c|c|}
\hline American & $\hat{\phi}$ & $\hat{\lambda}_{1}\left(\frac{\phi}{1-\hat{\phi}}\right)$ & $\hat{\lambda}_{0}$ (reported rapes & power $=\operatorname{Pr}($ accept & $\left(\frac{\hat{\phi}}{1-\hat{\phi}}\right)(\#$ fear- \\
\hline $\begin{array}{l}\text { Nations } \\
(\mathrm{r}=14)\end{array}$ & (Prop fear) & $\begin{array}{l}\text { (unreported rapes } \\
\text { under fear) }\end{array}$ & without fear) & true $\left.\phi_{*}=0.5\right)$ & for 10 Non-fear \\
\hline Argentina & 0.11 & 364 & 3321 & 0.01 & 1 \\
\hline Bolivia & $0.78 * *$ & 1191 & 1516 & 0.20 & 36 \\
\hline Canada & 0.17 & 88 & 509 & 0.48 & 2 \\
\hline Chile & $0.87 * *$ & 1846 & 2106 & 0.56 & 70 \\
\hline Colombia & $0.99 * *$ & 22835282 & 3379 & 0.91 & 33790 \\
\hline Grenada & $0.96 * *$ & 1800 & 30 & 0.91 & 300 \\
\hline Guatemala & $0.72 * *$ & 256 & 351 & 0.67 & 26 \\
\hline Mexico & $0.31 * *$ & 8675 & 14138 & 0.01 & 4 \\
\hline Panama & $0.85 * *$ & 670 & 784 & 0.74 & 59 \\
\hline Peru & $0.78 * *$ & 5811 & 7384 & 0.01 & 36 \\
\hline Saint Vincent & $0.71 * *$ & 34 & 48 & 0.88 & 25 \\
\hline Trinidad and Tobago & $0.84 * *$ & 233 & 276 & 0.91 & 54 \\
\hline USA & $0.89 * *$ & 82451 & 91680 & 0.01 & 89 \\
\hline
\end{tabular}


Table 3. Rapes in Asia $(* *=$ p-value $<0.001, *$ - p-value $<0.01)$

\begin{tabular}{|c|c|c|c|c|c|}
\hline American & & $\hat{\lambda}_{1}\left(\frac{\phi}{1-\hat{\phi}}\right)$ & & & \\
\hline Nations & $\hat{\phi}$ & (unreported rapes & $\hat{\lambda}_{0}$ (reported rapes & power $=\operatorname{Pr}($ accept & $\left(\frac{\hat{\phi}}{1-\hat{\phi}}\right)(\#$ fear- \\
\hline$(\mathrm{r}=14)$ & (Prop fear) & under fear) & without fear) & true $\left.\phi_{*}=0.5\right)$ & for 10 Non-fear \\
\hline Armenia & $0.67^{*}$ & 6 & 10 & 0.84 & 20 \\
\hline Azerbaijan & 0.16 & 4 & 29 & 0.99 & 1 \\
\hline Bahrain & $0.6^{* *}$ & 16 & 28 & 0.78 & 14 \\
\hline Georgia & $0.85^{* *}$ & 108 & 128 & 0.91 & 56 \\
\hline Hong Kong & $0.96 * *$ & 5409 & 106 & 0.91 & 260 \\
\hline India & $0.85 * *$ & 18004 & 21102 & 0.01 & 58 \\
\hline Israel & $0.55 * *$ & 2383 & 1256 & 0.13 & 12 \\
\hline Japan & $0.82 * *$ & 1372 & 1674 & 0.22 & 45 \\
\hline Kazakhstan & $0.89 * *$ & 1246 & 1406 & 0.75 & 77 \\
\hline Kuwait & 0.06 & 7 & 128 & 0.99 & 0 \\
\hline Kyrgyzstan & $0.97 * *$ & 19606 & 301 & 0.91 & 330 \\
\hline Maldives & 0.07 & 0 & 7 & 0.99 & 0 \\
\hline Mongolia & $0.99 * *$ & 250632 & 354 & 0.91 & 3540 \\
\hline Oman & $0.78 * *$ & 123 & 157 & 0.89 & 36 \\
\hline Philippines & $0.72 * *$ & 1803 & 2497 & 0.01 & 26 \\
\hline Syria & $0.55 * *$ & 76 & 140 & 0.65 & 12 \\
\hline Tajikistan & 0.23 & 18 & 51 & 0.99 & 2 \\
\hline Thailand & $0.93 * *$ & 4542 & 4896 & 0.58 & 128 \\
\hline Yemen & $0.59 * *$ & 83 & 141 & 0.75 & 14 \\
\hline
\end{tabular}

Impact of fear on unreporting in Africa

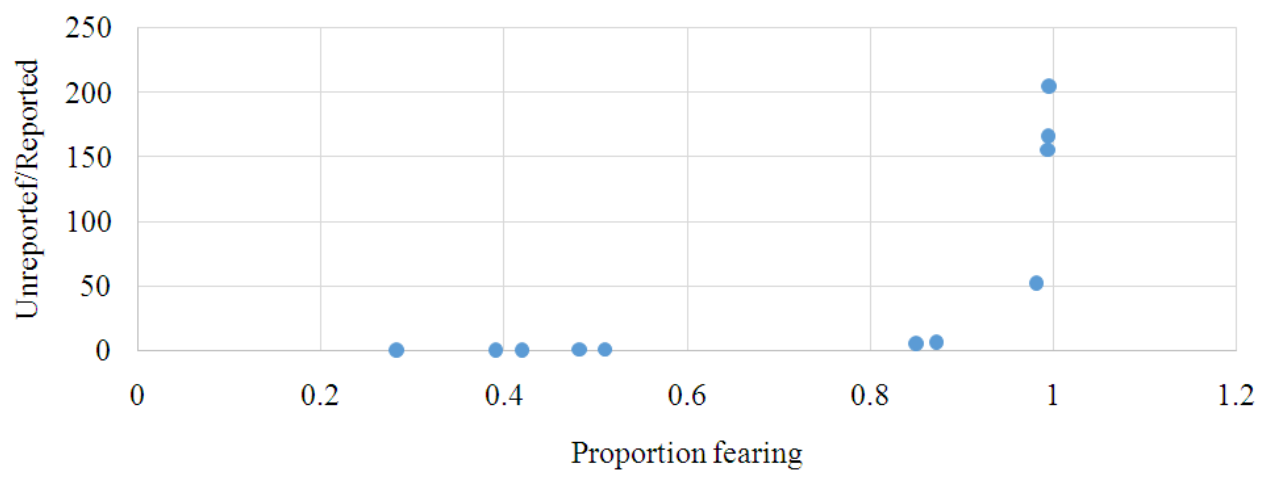

Fig. 2. Ratio of unreported over reported rapes versus proportion of fearing in Africa

There are more fearing in Kenya, Senegal, Sierra Leone, South Africa, Uganda, Zimbabwe in Africa, Bolivia, Chile, Colombia, Grenada, Guatemala, Panama, Peru, St. Vincent, Trinidad and Tobago, USA in Americas, Armenia, Bahrain, Georgia, Hong Kong, India, Israel, Japan, Kazakhstan, Kyrgyzstan, Mongolia, Oman, Philippines, Syria, Thailand, Yemen in Asia, Albania andorra, Austria, Belarus, Cyprus, Czech, Denmark, Estonia, Finland, Germany, Greece, Hungary, Ireland, Latvia, Lithuania, Netherlands, Norway, Poland Portugal, Russia, Slovenia, Sweden,
UK (England and Wales), Ukraine and UK (Scotland) in Europe, Australia, New Zealand, Solomon Islands in Pacific.

The Fig. 2-6 attest that the ratio of unreported over the reported rapes increases along with the increasing proportion fearing in all continents. The Colombia and Grenada display an unusual ratio of unreported over reported rapes. These findings become possible because of the BPD (4) as an underlying model for the reported rape data. This article confirms the existence of fear factor as hinted in the CPR (2007). 
Table 4. Rapes in Europe $(* *=\mathrm{p}$-value $<0.001, *$ - p-value $<0.01)$

\begin{tabular}{|c|c|c|c|c|c|}
\hline American & $\hat{\phi}$ & $\hat{\lambda}_{1}\left(\frac{\phi}{1-\hat{\phi}}\right)$ (unreported & $\hat{\lambda}_{0}$ (reported rapes & Power $=\operatorname{Pr}($ accept & $\left(\frac{\hat{\phi}}{1-\hat{\phi}}\right)(\#$ fear- \\
\hline Nations $(r=4)$ & (Prop fear) & rapes under fear) & without fear) & true $\left.\phi_{*}=0.5\right)$ & for 10 Non-fear \\
\hline Albania & $0.90 * *$ & 723 & 40 & 0.91 & 95 \\
\hline Andorra & 0.50 & 2 & 1 & 0.01 & 10 \\
\hline Austria & $0.66^{* *}$ & 2242 & 701 & 0.21 & 19 \\
\hline Belarus & $0.88^{* *}$ & 254 & 288 & 0.92 & 75 \\
\hline Belgium & $0.28 * *$ & 881 & 3179 & 0.01 & 3 \\
\hline Bosnia and Herzegovina & 0.01 & 0 & 39 & 0.99 & 0 \\
\hline Bulgaria & 0.48 & 115 & 243 & 0.54 & 9 \\
\hline Croatia & $0.32 *$ & 55 & 175 & 0.79 & 4 \\
\hline Cyprus & $0.62 * *$ & 16 & 26 & 0.81 & 16 \\
\hline Czech & $0.82 * *$ & 477 & 583 & 0.73 & 45 \\
\hline Denmark & $0.82 * *$ & 365 & 444 & 0.90 & 46 \\
\hline Estonia & $0.67 * *$ & 94 & 141 & 0.84 & 20 \\
\hline Finland & $0.90 * *$ & 743 & 827 & 0.91 & 88 \\
\hline France & 0.01 & 151 & 10204 & 0.99 & 0 \\
\hline Germany & $0.53 * *$ & 3910 & 7401 & 0.01 & 11 \\
\hline Greece & $0.68 * *$ & 142 & 208 & 0.84 & 21 \\
\hline Hungary & $0.99 * *$ & 91592 & 214 & 0.91 & 2140 \\
\hline Iceland & $0.40 * *$ & 30 & 77 & 0.89 & 6 \\
\hline Ireland & $0.79 * *$ & 2435 & 352 & 0.89 & 318 \\
\hline Latvia & $0.60 * *$ & 226 & 96 & 0.77 & 14 \\
\hline Lithuania & $0.56^{* *}$ & 102 & 182 & 0.68 & 12 \\
\hline Luxembourg & 0.25 & 12 & 50 & 0.99 & 3 \\
\hline Malta & $0.47 *$ & 6 & 14 & 0.58 & 8 \\
\hline Moldova & 0.03 & 9 & 293 & 0.99 & 0 \\
\hline Netherlands & $0.77 * *$ & 1542 & 2007 & 0.06 & 33 \\
\hline Norway & $0.99 * *$ & 1782272 & 944 & 0.91 & 9439 \\
\hline Poland & $0.86^{* *}$ & 1483 & 1719 & 0.55 & 62 \\
\hline Portugal & $0.77 * *$ & 1817 & 309 & 0.88 & 33 \\
\hline Romania & $0.36^{* *}$ & 806 & 1031 & 0.01 & 5 \\
\hline Russia & $0.96 * *$ & 6373 & 6623 & 0.92 & 255 \\
\hline Serbia & 0.17 & 19 & 114 & 0.99 & 2 \\
\hline Slovakia & $0.46^{* *}$ & 76 & 167 & 0.66 & 8 \\
\hline Slovenia & $0.82 * *$ & 63 & 77 & 0.91 & 46 \\
\hline Spain & $0.27 * *$ & 671 & 2483 & 0.01 & 3 \\
\hline Sweden & $0.96 * *$ & 4887 & 5097 & 0.92 & 233 \\
\hline Switzerland & 0.01 & 8 & 630 & 0.99 & 0 \\
\hline Turkey & $0.46^{*}$ & 505 & 1109 & 0.07 & 8 \\
\hline UK (England and Wales) & $0.75^{* *}$ & 9640 & 12884 & 0.01 & 29 \\
\hline UK (Northern Ireland) & $0.26^{*}$ & 171 & 378 & 0.38 & 3 \\
\hline Ukraine & $0.99 * *$ & 384566 & 879 & 0.91 & 2192 \\
\hline UK (Scotland) & $0.63 * *$ & 542 & 864 & 0.17 & 16 \\
\hline
\end{tabular}

Table 5. Rapes in pacific $(* *=p$-value $<0.001, *$ - p-value $<0.01)$

\begin{tabular}{llllll}
\hline Sampled Pacific & $\hat{\phi}$ & $\hat{\lambda}_{1}\left(\frac{\hat{\phi}}{1-\hat{\phi}}\right)$ & $\hat{\lambda}_{0}$ (reported rapes & Power $=\operatorname{Pr}(\operatorname{accept}$ & $\left(\frac{\hat{\phi}}{1-\hat{\phi}}\right)(\#$ fear- \\
Nations $(\mathrm{r}=14)$ & (Prop fear) & $\begin{array}{l}\text { (unreported rapes } \\
\text { under fear) }\end{array}$ & without fear) & true $\left.\phi_{*}=0.5\right)$ & for 10Non-fear \\
\hline Australia & $0.79^{* *}$ & 41863 & 6362 & 0.010 & 62 \\
New Zealand & $0.86^{* *}$ & 13169 & 1136 & 0.740 & 18 \\
Solomon Islands & $0.65^{*}$ & 177 & 58 & 0.838 & 36 \\
\hline
\end{tabular}


Ramalingam Shanmugam / American Journal of Biostatistics 3 (1): 17-29, 2013

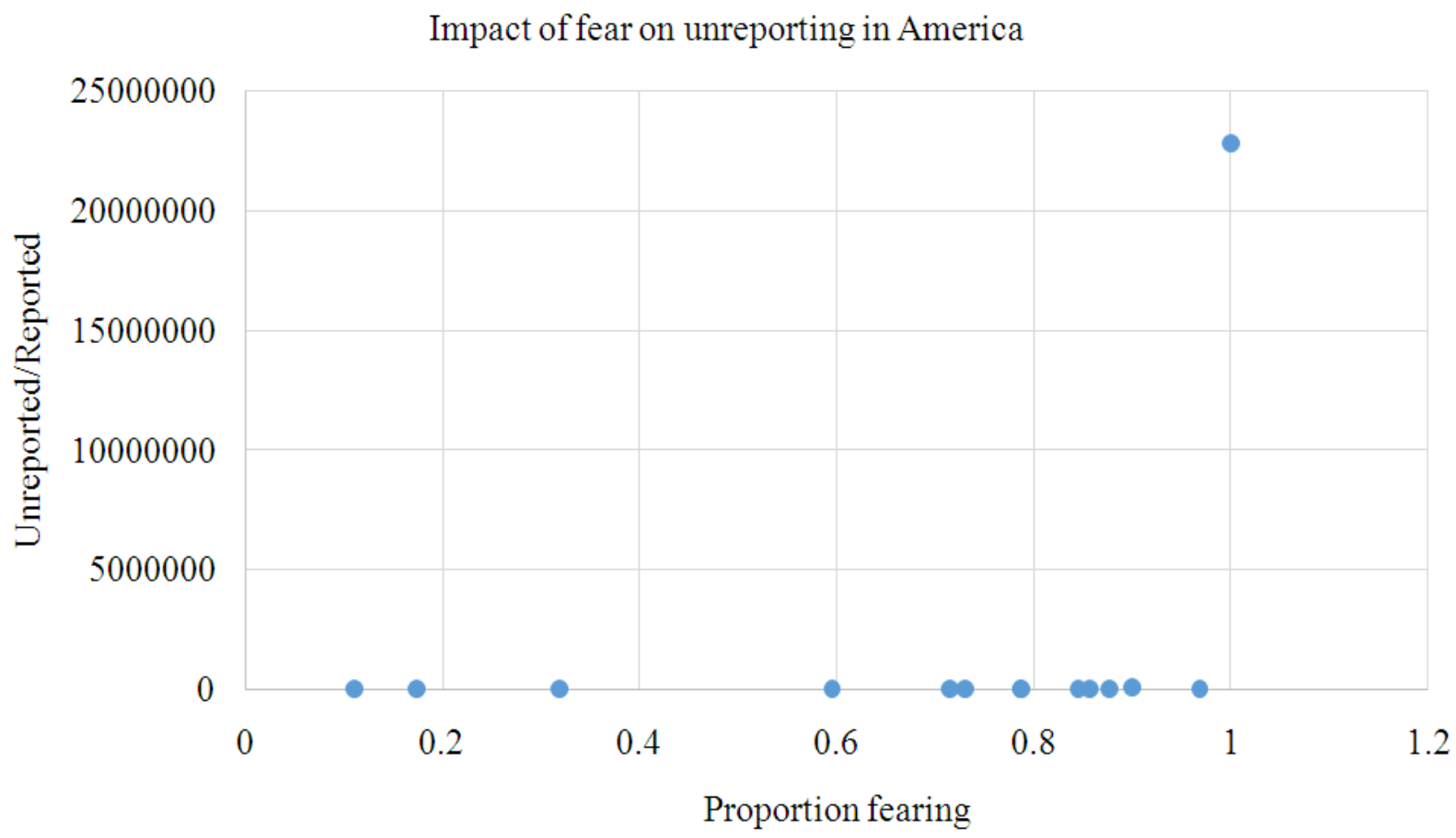

Fig. 3. Ratio of unreported over reported rapes versus proportion of fearing in America

Impact of fear on unreporting in Asia

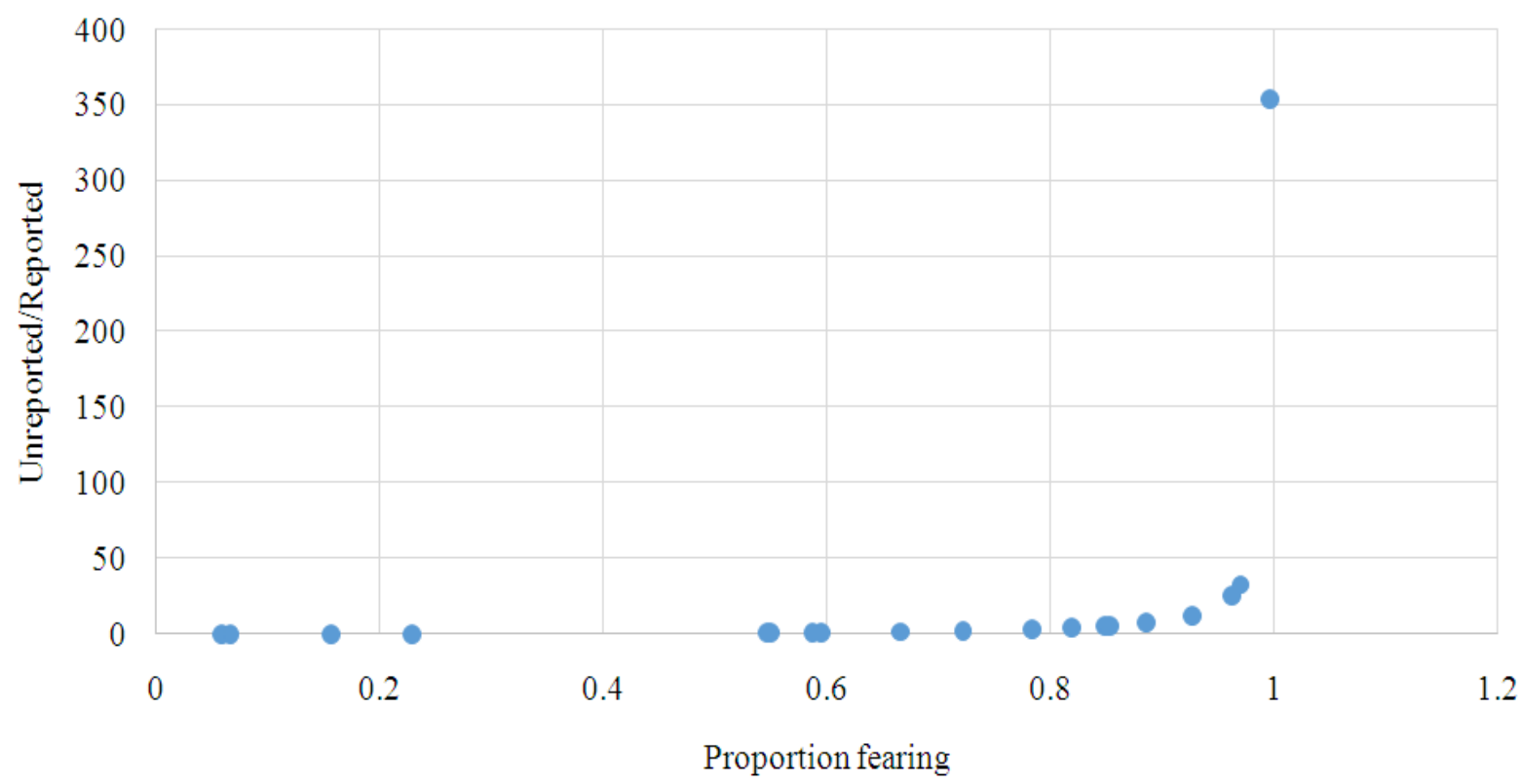

Fig. 4. Ratio of unreported over reported rapes versus proportion of fearing in Asia 
Ramalingam Shanmugam / American Journal of Biostatistics 3 (1): 17-29, 2013

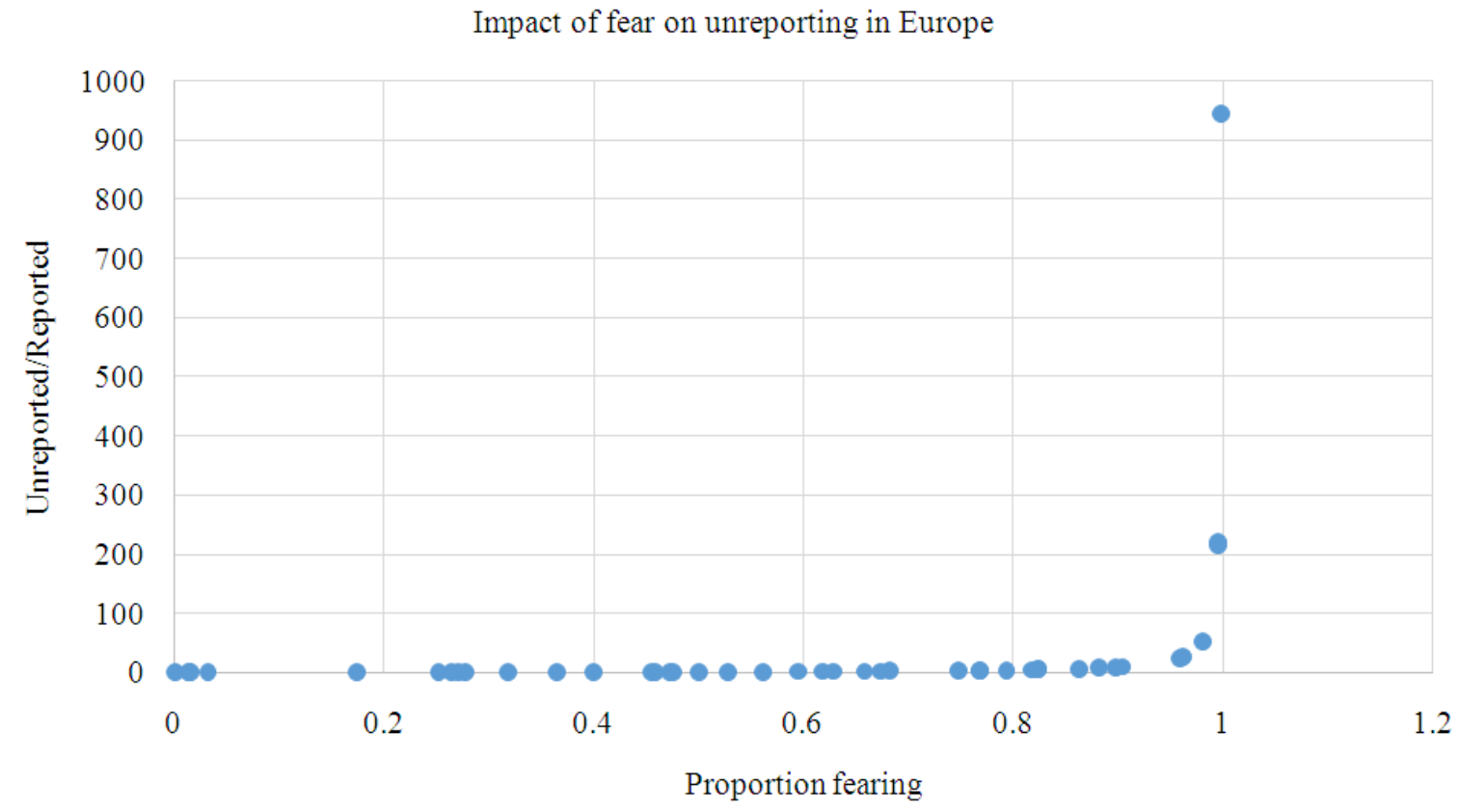

Fig. 5. Ratio of unreported over reported rapes versus proportion of fearing in Europe

Impact of fear on unreporting in Pacific islands

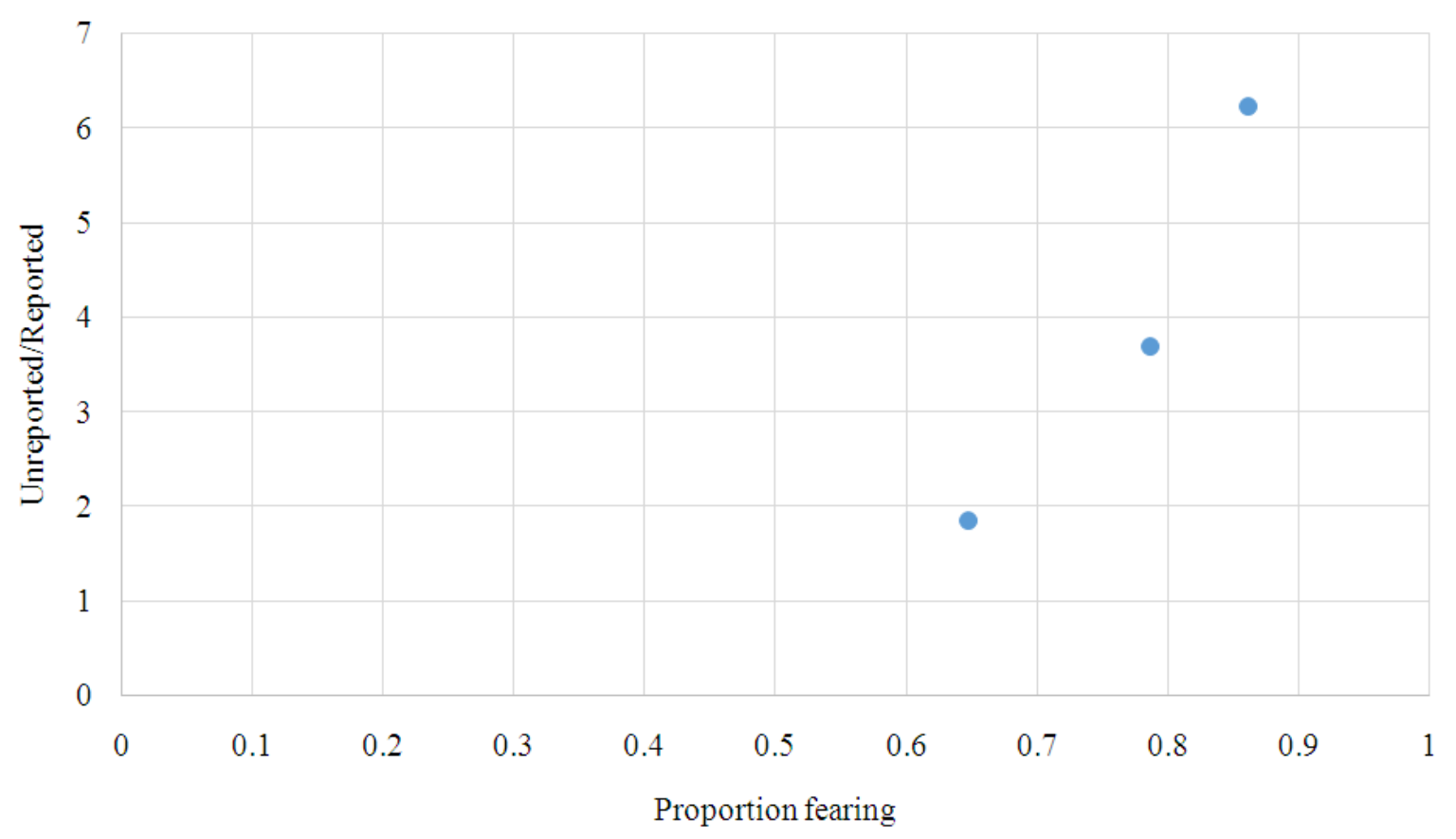

Fig. 6. Ratio of unreported over reported rapes versus proportion of fearing in Pacific 
Ramalingam Shanmugam / American Journal of Biostatistics 3 (1): 17-29, 2013

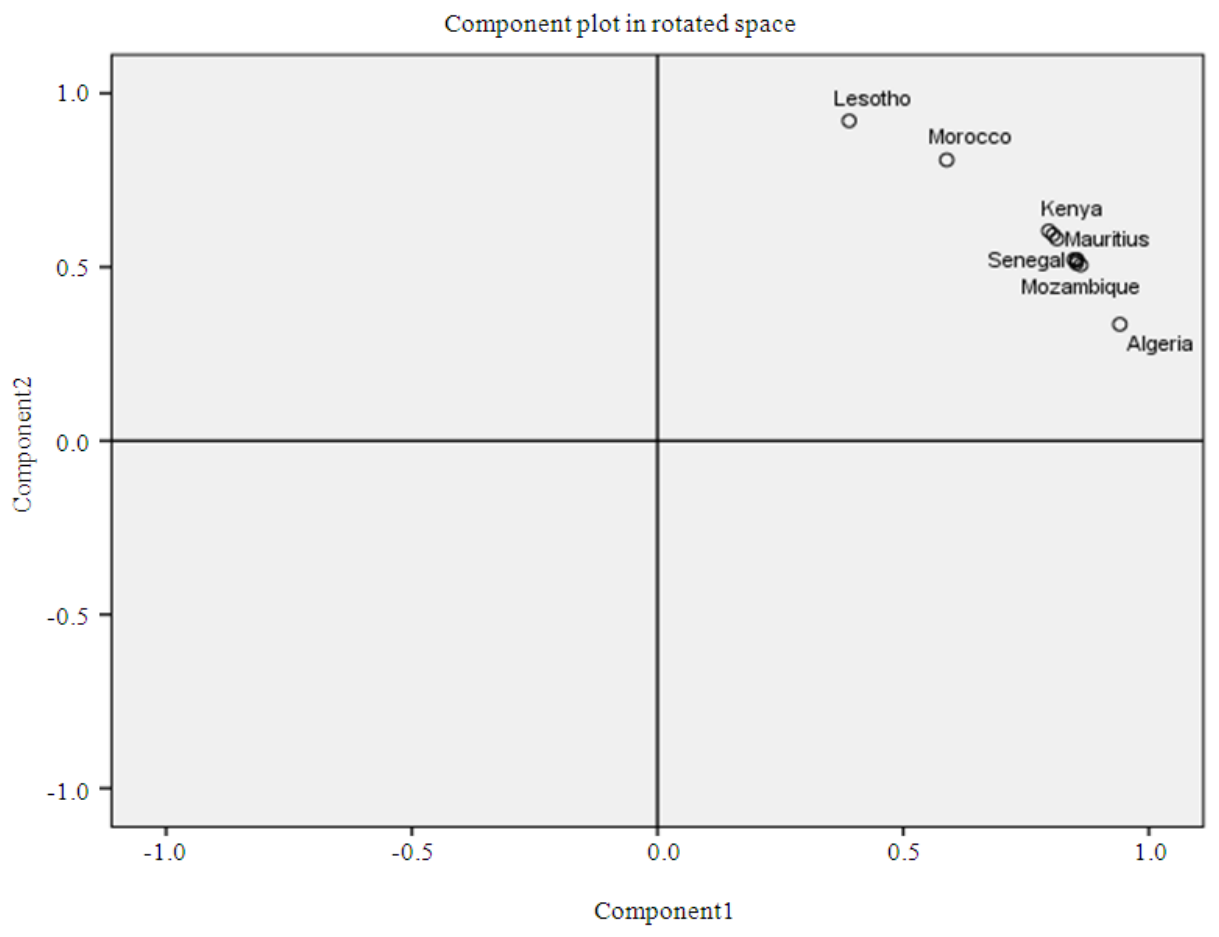

Fig. 7. Proximity among African nations

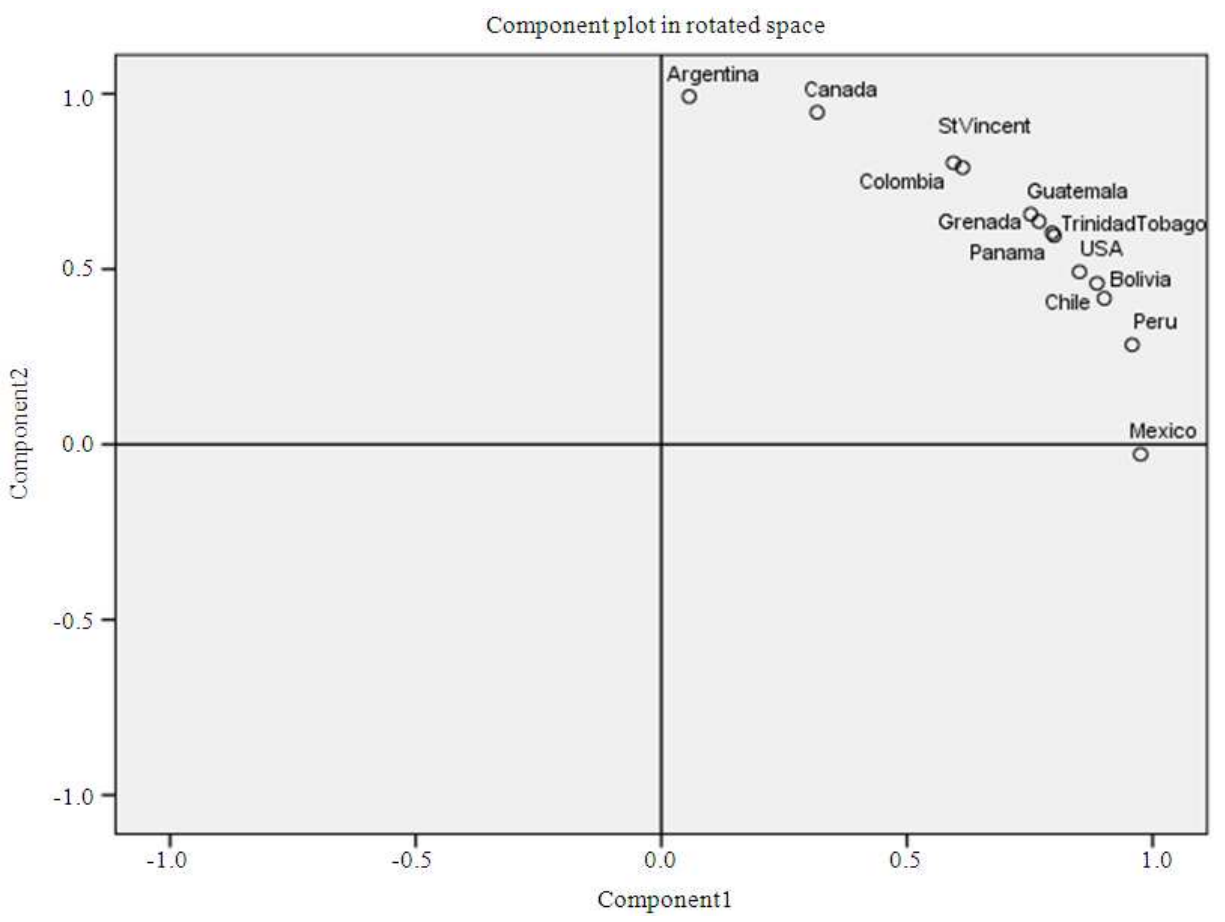

Fig. 8. Proximity among American nations 
Ramalingam Shanmugam / American Journal of Biostatistics 3 (1): 17-29, 2013

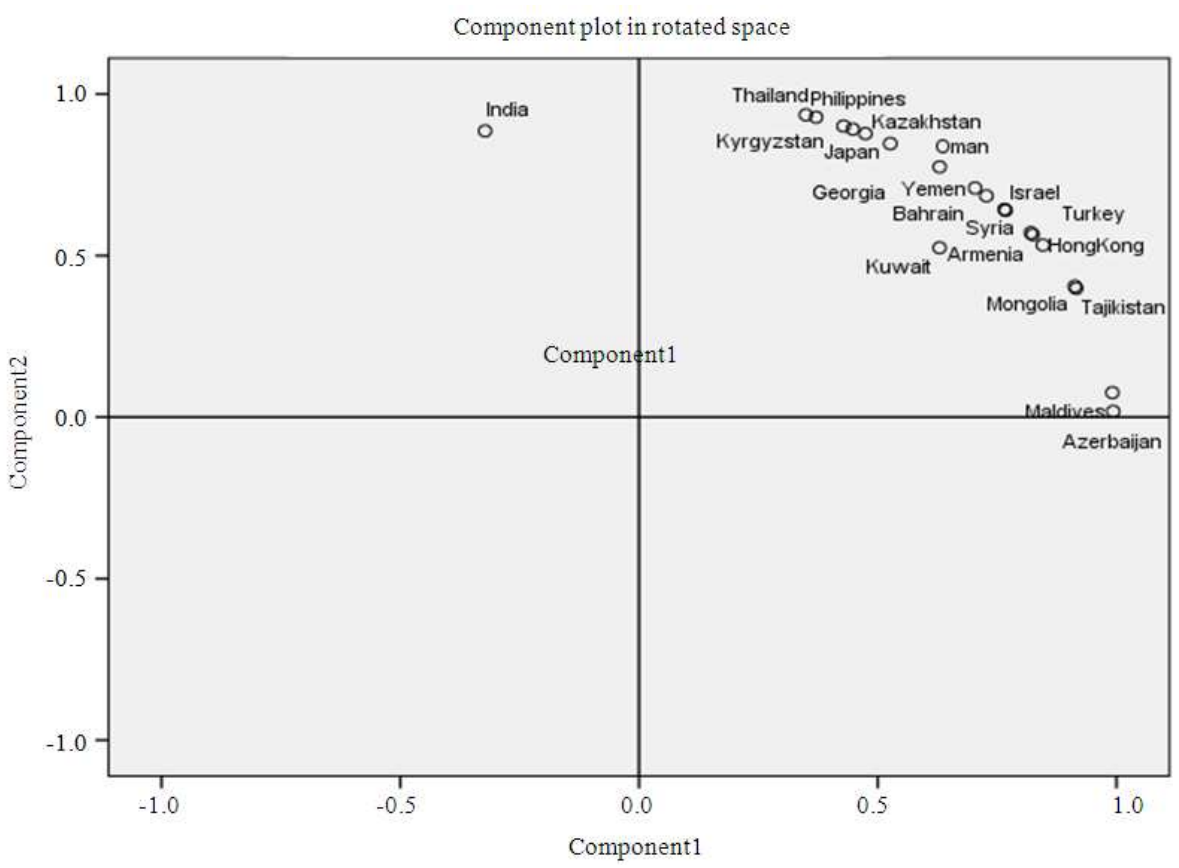

Fig. 9. Proximity among Asian nations

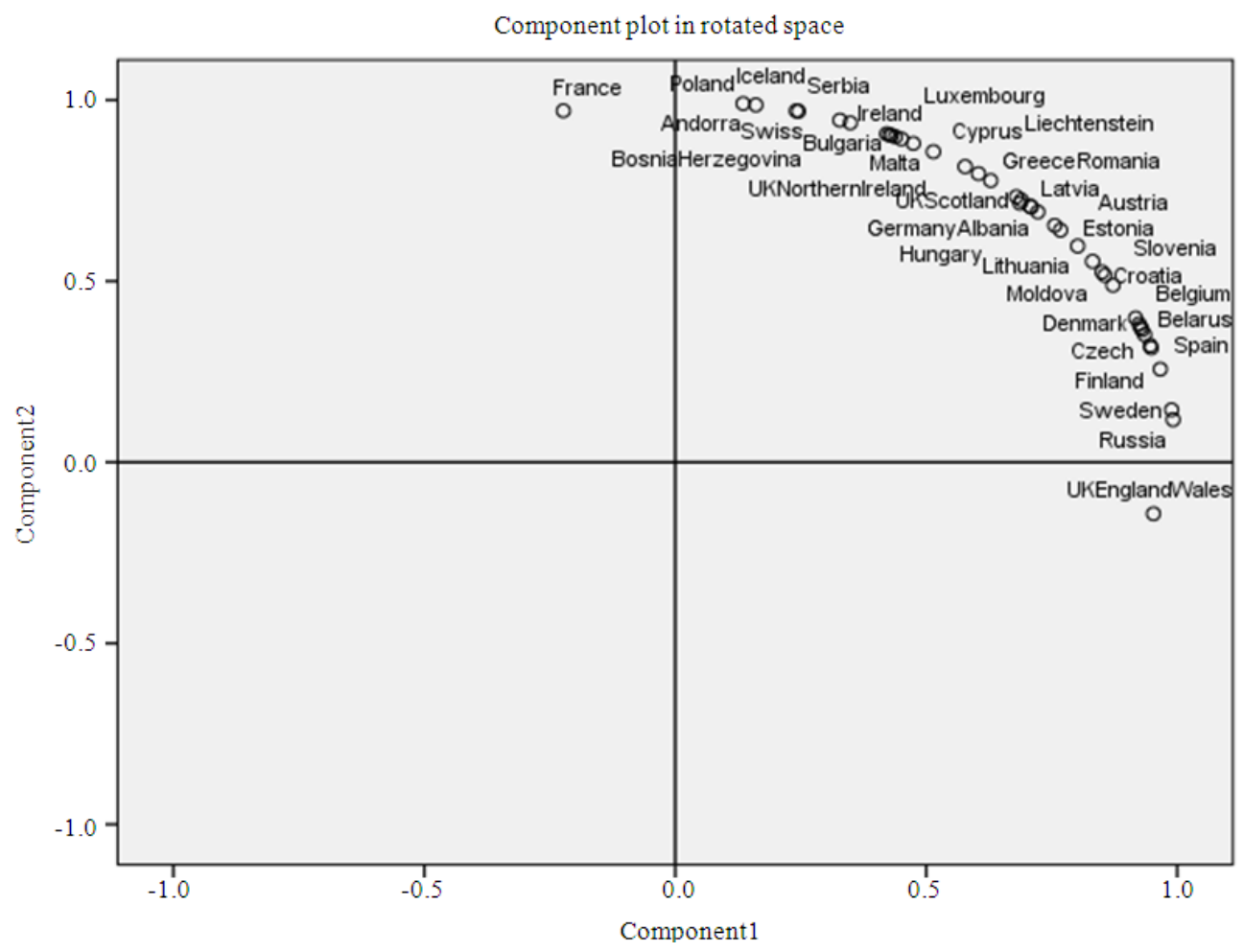

Fig. 10. Proximity among European nations 


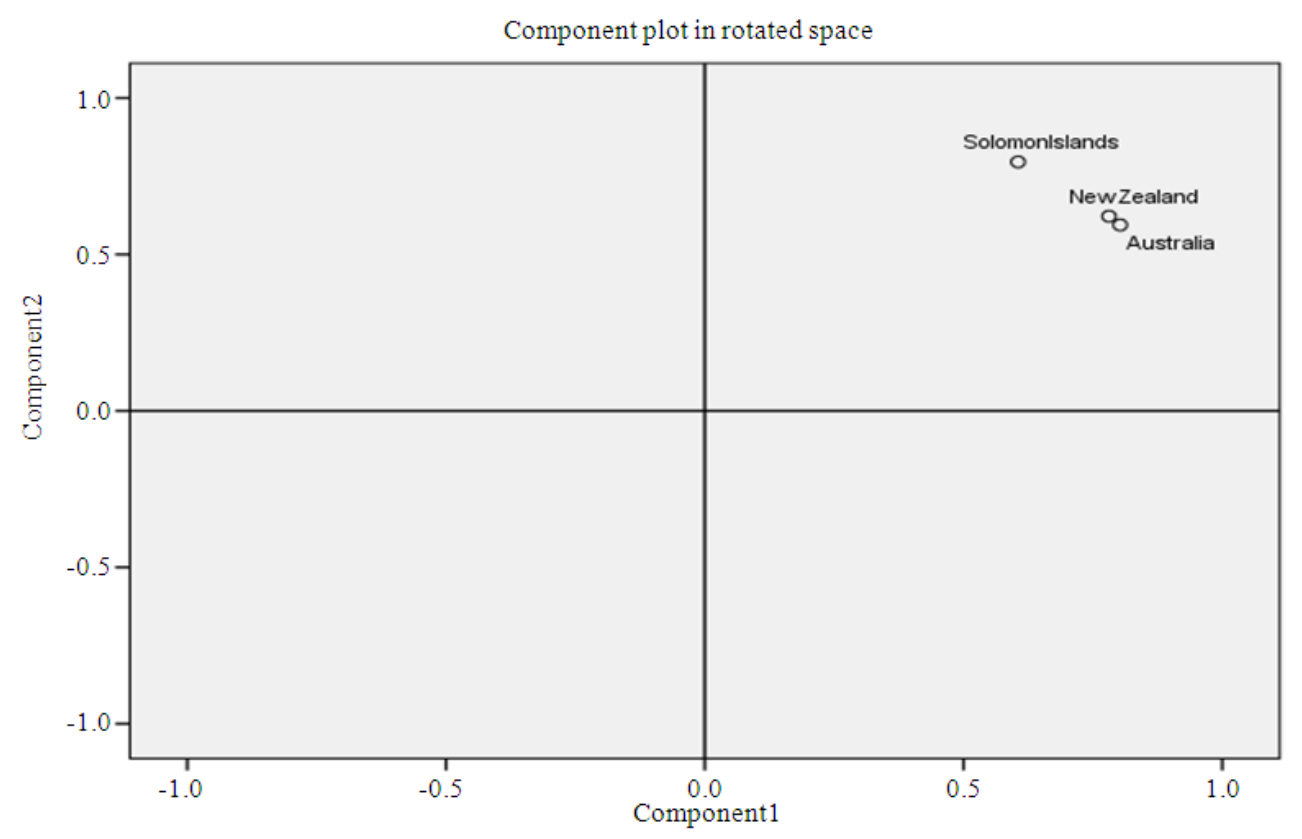

Fig. 11. Proximity among pacific nations

\section{CONCLUSION}

All continents have mixed scenarios with respect to the reported and unreported rapes due to fear. The proportion fearing varies within every continent. Some nations have closer proximities (Fig. 7-11) with respect to fear to report rape, according to a PCA on the results in Table 2-5. Algeria differs from Lesotho in Africa, Argentina differs from Mexico in Americas, India differs from Azerbaijan in Asia, France differs from UK (England and Wales) in Europe and Solomon Island differs from Australia in Pacific. More needs to be explored to prevent this dreadful crime called rape.

\section{REFERENCES}

Abrahms, D., G.V. Tendayi, B. Masser and G. Bohner, 2003. Perceptions of stranger and acquaintance rape: The role of benevolent and hostile sexism in victim blame and rape proclivity. J. Personality Social Psychol., 84: 111-125. DOI: 10.1037/00223514.84.1.111

Buddie, A.M. and A.G. Miller, 2001. Beyond rape myths: A more complex view of perceptions of rape victims. Sex Roles, 45: 139-160. DOI: 10.1023/A:1013575209803
CPR, 2007. Without consent: A report on the joint review of the investigation and prosecution of rape offences. Crown Prosecution Report, Central Office of Information, London, England.

Macdonalds, J., 2003. Rape. In: The World Book Encyclopedia, World Book Inc., New York. ISBN-10: 0716601036, pp: 10000-10000.

Marnie, E., D. Rice, M.L. Lalumiere, L. Vernon and P. Quinsey, 2005. The Causes of Rape: Understanding Individual Differences in Male Propensity for Sexual Aggression. 1st Edn., American Psychological Association, Washington, ISBN-10: 1591471869, pp: 294.

McKibbin, W.F., T.K. Shackelford, A.T. Goetz and V.G. Starratt, 2008. Why do men rape? An evolutionary psychological perspective. Rev. General Psychol., 12: 86-97. DOI: 10.1037/1089-2680.12.1.86

Pauwels, B., 2002. Blaming the victim of rape: The culpable control model perspective. Ph.D. Thesis, University of Iowa.

Schott, J.R., 2005. Matrix Analysis for Statistics. 2nd Edn., John Wiley Press, Hoboken, NJ, ISBN-10: 0471669830, pp: 480.

Sivaprakash, P. and M. Sakthivel, 2010. A comparative study on safety and security management systems in industries. Am. J. Environ. Sci., 6: 548-552. DOI: 10.3844/ajessp.2010.548.552 
Stuart, A. and K. Ord, 2009. Kendall's Advanced Theory of Statistics. 6th Edn., Wiley, London, U.K., ISBN10: 0340614307, pp: 700.

Thornhill, R. and C.T. Palmer, 2000. A Natural History of Rape: Biological Bases of Sexual Coercion. MIT Press, Cambridge, ISBN-10: 0262201259, pp: 251.
Wald, A., 1943. Tests of statistical hypotheses concerning several parameters when the number of observations is large. Trans. Am. Math. Soc., 54: 426-482. DOI: 10.1090/S0002-9947-19430012401-3 